\title{
MIMIKRI SEBAGAI UPAYA MELAWAN DALAM NOVEL GADIS PANTAI KARYA PRAMOEDYA ANANTA TOER
}

\author{
Ardiyanto Wibisono ${ }^{1}$, Herman J. Waluyo², Slamet Subiyantoro ${ }^{3}$ \\ Universitas Sebelas Maret \\ J1. Ir. Sutami 36 A Kentingan, Surakarta 57126 \\ yan.wibisono@ymail.com ${ }^{1}$
}

\begin{abstract}
ABSTRAK
Artikel ini berusaha mendeskripsikan bentuk mimikri sebagai upaya untuk melawan dengan menggunakan kajian poskolonial. Novel Gadis Pantai karya Pramoedya Ananta Toer digunakan sebagai objek penelitian lalu dianalisis dengan pendekatan poskolonial untuk mencari bentuk mimikri yang ada dalam novel tersebut. Penelitian ini menggunakan kajian deskriptif analitis dengan menggunakan sumber data novel Gadis Pantai. Penelitian ini menggambarkan bagaimana perbedaan status sosial yang menyebabkan inferioritas dari stastus sosial tertentu yang kemudian melakukan peniruan atau mimikri untuk melakukan perlawanan. Gadis Pantai merupakan tokoh utama yang melakukan mimikri kemudian melawan sistem kebangsawanan Bendoro untuk mempertahankan harga diri dan keluarganya.
\end{abstract}

Kata kunci: gadis pantai, mimikri, poskolonial

\section{A. PENDAHULUAN}

Kolonialisasi yang terjadi 3,5 abad di Indonesia tentu membuat kesan mendalam bagi bangsa ini. Sebagai negara yang pernah dijajah dengan sejarah panjang akan membetuk segala sesuatu yang ada di dalamnya baik disadari atau tidak. Kolonialisasi telah menghasilkan identitasidentitas baru dan identitas ganda bagi masyarakat negara terjajah. Muncul identitas hibrid, mimikri, dan juga perbedaan kelas sosial yang semakin tajam menjadi salah satu ciri masyarakat negara yang pernah terjajah. Lingkungan sosial dan kebudayaan merupakan unsur yang memiliki kesan mendalam bagi negara yang pernah dijajah.
Sastra sebagai bentuk dari kebudayaan itu sendiri tentu juga ikut terpengaruh. Teeuw berpendapat bahwa karya sastra tidak terlahir dari kekosongan budaya. Novel Gadis Pantai karya Pramoedya Ananta Toer merupakan salah satu karya sastra yang merekam kondisi sosial masyarakat sebagai akibat dari kolonialisasi.

Kolonialisme menurut istilah adalah penaklukan atau penguasaan wilayah yang dikuasai penduduk asli oleh pendatang (Loomba, 1998: 1-42). Konotasi negatif kolonial terjadi karena interaksi yang tidak seimbang antara penduduk pribumi yang dikuasai dengan penduduk pendatang (Ratna, 2004: 205). Sedangkan poskolonial, 


\section{DEIKSIS - JURNAL PENDIDIKAN BAHASA DAN SASTRA INDONESIA}

menurut Makaryk didefinisikan sebagai strategi teoretis dan kritis yang memiliki asumsi untuk mempersoalkan posisi subjek kolonial dan pascakolonial (1993: 14). Lebih jelas tentang posisi terjajah dan penjajah dapat dipahami pandangan penjajah terhadap penjajah merupakan wilayah orientalisme, sedangankan pandangan terjajah terhadap penjajah merupakan wilayah poskolonialisme (Efendi, 2016: 228). Sebagai teori kritis, poskolonial mengeksplorasi kondisi diskursif setelah kolonialisasi, hubungan-hubungan kolonial, dan kelanjutannya. Poskolonialisme juga dapat dilihat dari resistensi teoretis terhadap hal-hal yang terlupakan setelah kolonialisme. Poskolonial juga merupakan tugas akademik untuk mengkaji kembali dan menyelidiki untuk mengungkapkan wacana kolonial (Ghandi, 1998:4). Teori poskolonial mempelajari wacana-wacana poskolonial dan posisi-posisi subjeknya, dalam kaitannya dengan tema-tema tentang ras, bangsa subjektivitas, subaltern, hibriditas, dan kreolisasi (Barker, 2005: 519).

Novel Gadis Pantai merupakan gambaran interaksi masyarakat dengan kelas sosial yang berbeda. Interaksi yang terjadi antara tokoh Gadis Pantai yang berasal dari masyarakat pesisir dan seorang Bendoro dari keluarga bangsawan. Pertemuan antara Gadis Pantai dan Bendoro merupakan hal yang sudah direncanakan orang tua Gadis Pantai yang ingin menikahkan anaknya dengan seorang yang dinggap memiliki kelas sosial lebih tinggi yaitu seorang Bendoro. Gadis Pantai yang berasal dari masyarakat pesisir dipaksa untuk beradaptasi dengan lingkungan dan gaya hidup keluarga bangsawan, baik secara tuturan maupun perbuatan. Dari interaksi antara Gadis Pantai dan lingkungan barunya di keluarga bangsawan identitas baru yang hibrid bersifat mimikri yang muncul dalam diri Gadis Pantai.

Menurut Bhaba (Faruk, 2001: 6), konsep hibriditas digunakan untuk menggambarkan bergabungnya dua bentuk yang memunculkan sifat-sifat tertentu dari masing-masing bentuk dan sekaligus juga meniadakan sifat-sifat tertentu yang dimiliki keduanya. Terminologi dunia ketiga dan dunia pertama juga menjadi dua kata kunci teori Bhabha. Bhabha mengemukakan mimikri sebagai bukti bahwa yang terjajah tidak selalu diam, tetapi juga memiliki kuasa untuk melawan. Konsep mimikri digunakan untuk mengggambarkan proses peniruan atau peminjaman berbagai elemen kebudayaan.

Mimikri merupakan meniru, implikasi menggunakan alat lain dalam proses membangun identitas pasca-kolonial. Dalam hal ini, merupakan interaksi antara gadis Pantai dan Bendoro. Pengaruh tersebut berdampak pada pembentukan identitas terhadap status sosial di bawahnya (Brown, 2016: 157). Permasalahan yang terjadi pada masyarakat terjajah menghadapi wacana penjajah adalah masalah emansipasi melalui cara peniruan atau mimikri yang ambivalen. Satu pihak membangun identitas atau persamaan, tetapi di lain pihak mempertahankan perbedaan (Faruk, 2001: 72). Penelitian ini bertujuan untuk mendeskripsiakan mimikri dalam novel Gadis Pantai karya Pramoedya 


\section{DEIKSIS - JURNAL PENDIDIKAN BAHASA DAN SASTRA INDONESIA}

Ananta Toer dengan menggunakan kajian poskolonial.

\section{B. METODE PENELITIAN}

Penelitian ini dilakukan dengan pendekatan kualitatif. Sumber data yang dikaji berupa Novel Gadis Pantai karya Pramoedya Ananta Toer yang diterbitkan oleh Lentera Dipantara tahun 2003. Menurut Ratna (2004:46), penelitian kualitatif dilakukan semata-mata untuk menguraikan fakta mengenai suatu gambaran dengan apa adannya atau alamiah dalam bentuk deskripsi, yaitu dengan kata-kata tertulis atau lisan dari subjek yang diteliti. Data pada penelitian ini adalah dokumen tertulis berupa kata, kalimat, dan paragraf dalam novel Gadis Pantai yang menunjukkan mimikri.

Teknik pengumpulan data yang digunakan dalam penelitian ini adalah teknik dokumentasi. Teknik dokumentasi adalah teknik pencarian data mengenai hal-hal atau variabel yang berupa catatan, transkrip, buku, surat kabar, majalah, prasasti, notulen rapat, lengger, agenda, dan sebagainya (Arikunto, 2013: 274). Pengumpulan data mengenai dilakukan dengan: (a) membaca secara berulang-ulang dengan teliti, (b) menyeleksi data, dan (c) melakukan kodefikasi pada setiap temuan. Teknik analisis data penelitian ini terdiri dari tiga alur kegiatan, seperti yang diungkapkan oleh Miles dan Huberman (1992: 16), yaitu reduksi data, penyajian data, dan penarikan simpulan.

\section{PEMBAHASAN}

\section{a. Mimikri Sebagai Upaya Melawan}

Novel Gadis Pantai merupakan karya sastra yang merekam kehidupan bangsawan Jawa. Perilaku bangsawan Jawa yang masih warga pribumi ternyata tidak jauh berbeda dari penjajahan yang dilakukan oleh bangsa asing karena sistem feodalisme justru terwariskan terhadap perilaku para bangsawan atau priyayi. Perbedaan status sosial yang dibuat semakin berjarak merupakan salah satu ciri bangsa yang pernah dijajah. Perbedaan antara ekonomi dan pendidikan menjadi hal yang sering ditonjolkan. Tokoh Gadis Pantai dalam novel Gadis Pantai harus berhadapan dengan lingkungan yang asing buat dirinya karena ia menikah dengan seorang Bendoro yang berasal dari keluarga bangsawan. Kini ia harus belajar mengaji, merawat diri, memberikan perintah kepada pelayannya, dan menjadi pelayan seorang Bendoro.

Hal pertama yang dilakukan Gadis pantai adalah belajar mengaji dan ilmu pengetahuan sebelum ia belajar untuk melayani Bendoro. Pada saat Gadis Pantai belajar ia sudah menunjukkan perilaku yang menyimpang, berbeda dengan istri Bendoro sebelumnya. Sebagaimana dalam kutipan berikut.

"Bingunglah sahaya ini, Mas Nganten, pertanyaan-pertanyaan begitu tak pernah sahaya dengar sumur hidup." (Gadis Pantai, hal. 86)

Kalau saja pelayan wanita itu begitu meyenangkan seperti itu! Tapi bertambah meningkat pengetahuan 


\section{DEIKSIS - JURNAL PENDIDIKAN BAHASA DAN SASTRA INDONESIA}

dan kecerdasannya, pelayan itu makin kurang kemampuan dalam menghibur hatinya. (Gadis Pantai, hal. 88)

Kutipan tersebut menunjukkan bahwa pendidikan yang dilalui oleh Gadis Pantai membawa perubahan pola pikir pada dirinya. Pola pikir yang baru membuatnya tidak lagi merasa nyaman dengan keadaannya. Tanpa disadari, perubahan sikap yang dilakukan Gadis Pantai merupakan bentuk mimikri yang dilakukan dari hasil pendidikan yang membuatnya menjadi memiliki identitas baru sebagai upaya untuk melawan dengan pemikirannya.

Masuknya Gadis Pantai ke kehidupan Bendoro tak serta merta diterima oleh lingkungan karena perbedaan status sosial masih menjadi hal yang penting pada saat itu. Ketidaksukaan tersebut diekspresikan oleh agus-agus yang merupakan abdi dalem Bendoro. Mereka berasal dari anak istri terdahulu yang telah diceraikan Bendoro. Agus-agus tersebut masuk ke kamar Gadis Pantai dan mencuri sejumlah uang. Sebagaimana dalam kutipan berikut.

"Baik, tidak ada yang mengaku. Sahaya Cuma orang kampung. Cuma sahaya. Tapi sahaya tahu apa mesti sahaya perbuat, agus-agus."

...

Nampak pemuda-pemuda itu menjadi pucat dan berpandang-pandangan satu sama lain.

"Baik tunggu agus-agus di sini. Sahaya akan urus. Sahaya akan tunjukkan orang kampung juga mengerti bagaimana berbuat. Tunggu sini bendoro-bendoro kecil," dan ia bimbing Gadis Pantai menuju pintu ke ruang dalam. (Gadis Pantai, hal. 112)

Kutipan tersebut menunjukkan bahwa Gadis Pantai sudah mencoba melakukan perlawanan sebagai upayanya mengungkap siapa yang mencuri uangnya di dalam kamarnya. Awalnya agus-agus tersebut tidak mengindahkan peringatan yang dilakukan oleh Gadis Pantai. Namun, pendidikan dan pengalaman yang ditempuhnya semasa menjadi seorang istri Bendoro membuatnya tahu bagaimana harus melawan dan berbuat dalam menghadapi situasi seperti itu. Nyali agusagus itu pun menciut karena tidak menyangka Gadis Pantai yang belum lama tinggal bersama mereka dan belum dianggap menjadi bagian dari keluarga bangsawan berani melawan agus-agus.

Mimikri postkolonial terjadi ketika subjek kolonial/postkolonial yang kurang kuat menggantikan pandangan penjajah yang kuat dengan meniru tindakan mereka, tetapi tidak pernah benar-benar menjadi mereka (Banerjee, 2014: 17). Untuk lebih jelas, hal tersebut digambarkan oleh Gadis Pantai yang melakukan mimikri sebagai upaya untuk melawan. Perlawanan yang dilakukan Gadis pantai sebenarnya dilakukan pada pelayan barunya sendiri. Hal tersebut terjadi karena pelayannya yang bernama Mardinah merasa dirinya memiliki status sosial yang lebih tinggi daripada Gadis Pantai. Sebagaimana dalam kutipan berikut. 


\section{DEIKSIS - JURNAL PENDIDIKAN BAHASA DAN SASTRA INDONESIA}

"Orang kota bangun! Menurut ukuran orang kampung tidak sopan tidur di tempat orang lain tanpa izin." Mardinah tertawa dan bangkit sendiri.

"Rupa-rupanya kau bisa menggeletak dan terlentang di mana-mana, di mana saja."

Ternyata Mardinah kebal tusukan kata. Ia masih juga tertawa. Dan tanpa terduga oleh Gadis Pantai keluar kata-katanya: "Ini, Mas Nganten," sambil menunjuk-nunjuk dadanya sendiri, "tak lain dan tak bukan adalah tubuh sahaya sendiri. Terserah pada sahaya taruh dan sahaya geletakan." (Gadis Pantai, hal. 127)

Kutipan tersebut menunjukkan bahwa Gadis Pantai menegur Mardinah yang dianggap berlaku taksopan dengan tidur di ranjang milik Gadis Pantai. Saat itu Gadis Pantai sudah menjadi istri Bendoro. Namun, tidakan itu mendapat reaksi yang sama ketika Mardinah juga takterima dengan teguran Gadis pantai. Mardinah merasa Gadis Pantai memiliki derajat lebih rendah karena keturuna nelayan, sementara dirinya merupakan keluarga seorang juru ketik. Interaksi yang terjadi selama Gadis Pantai berada di lingkungan keluarga bangsawan mengajarkannya untuk berani berbicara, sekalipun yang dihadapinya adalah seorang yang dianggap memiliki derajat sosial lebih tinggi.

Dalam mimikri, kolonial sebagai 'keinginan (kolonis) untuk orang-orang yang direformasi dan dikenali, sebagai subjek perbedaan yang hampir sama, tapi tidak cukup' (Watson, 2007: 174). Hal tersebut tergambar dalam sikap Mardinah yang menolak Gadis Pantai yang statusnya kini adalah seorang istri Bendoro sebagai seseorang bangsawan. Keberadaan Mardinah sebenarnya untuk melayani Gadis Pantai, namun Mardinah merasa dirinya lebih tinggi lantaran keluarganya berasal dari pensiunan juru ketik dan Gadis Pantai merupak keluarga seorang nelayan pesisir. Perlawanan yang dilakukan oleh Gadis pantai membuat Mardinah tidak bisa menerimanya. Sebagaimana dalam kutipan berikut.

Lenyaplah tawa dari wajah Mardinah. Dengan mata berapi-api ditantangnya Gadis Pantai dan dengan suara mengancam ia mengatakan, "Tidak mungkin orang kampung memerintah anak priyayi. Tidak bisa. Tidak mungkin."

Tapi Gadis Pantai telah menudingnya tepat pada matanya. "Keluar!"

Mardinah dengan kasar melemparkan lengan yang menuding matanya. Tapi Gadis Pantai meding dengan tangan yang lain. Kemudian "Juh!" Kemudian sepercik ludah bertengger pada hidung Mardinah. (Gadis Pantai, hal. 127)

Dalam kutipan tersebut, Gadis Pantai sadar dengan posisinya saat ini yang merupakan istri seorang Bendoro, sekalipun ia memiliki keluarga dengan status sosial lebih rendah dari Mardinah. Mardinah tak kehabisan akal, ia menantang Gadis Pantai dengan tatapan marah sambil membentak Gadis Pantai. Dengan posisinya saat ini, Gadis Pantai merespons pembangkangan yang dilakuakan oleh Mardinah dengan 


\section{DEIKSIS - JURNAL PENDIDIKAN BAHASA DAN SASTRA INDONESIA}

tindakan fisik, yakni meludahi muka Mardinah.

Mengenyam pendidikan di lingkungan keluarga bangsawan membuat Gadis Pantai berani berpikir dan bertindak sebagaimana yang dilakukan oleh Bendoro. Perlawanannya pun dilakukan kepada Bendoro ketika ia diceraikan dan dilarang mengasuh anak yang telah dilahirkannya. Anak tersebut akan menjadi abdi dalem keluarga Bendoro, bahkan Bendoro kaget saat Gadis Pantai melawan dengan menolak meninggalkan anaknya yang baru saja dilahirkan. Sebagaimana dalam kutipan berikut.

"Kau tak pernah sebanyak itu bicara." "Apakah yang takkan diperbuat seorang ibu buat anaknya."

"Kau tinggalkan rumah ini!..." (Gadis Pantai, hal. 257)

Dalam kutipan tersebut Gadis Pantai berani menentang perintah Bendoro untuk meninggalkan anaknya di rumah Bendoro setelah Gadis Pantai diceraikan secara sepihak oleh Bendoro. Hal tersebut sejalan dengan padangan Bhabha yang menemukan "mimikri" sebagai bukti bahwa yang terjajah tidak selalu diam karena mereka memiliki kuasa untuk melawan. Fenomena mimikri tidaklah menunjukkan ketergantungan sang terjajah kepada yang dijajah, tetapi peniru menikmati dan bermain dengan ambivalensi yang terjadi dalam proses imitasi tersebut. Konsep mimikri digunakan untuk menggambarkan proses peniruan atau peminjaman berbagai elemen kebudayaan (1994:84-92).
Peniruan perilaku dalam rangka melawan untuk membela dirinya. Gadis Pantai berani menentang Bendoro dan mempertahankan keluarga barunya yang merupakan anaknya sendiri. Ia sadar bahwa kekuasaan yang dilakukan oleh Bendoro mulai melanggar hak-haknya sebagai manusia. Sebagaimana pada kutipan berikut.

Gadis Pantai mengangkat muka, menantang mata Bendoro. Perlahanlahan ia bediri tegak dengan bayi dalam gendongannya.

"Ayam pun bisa membela anaknya, Bendoro. Apalagi sahaya ini-seorang manusia, biar pun sahaya tidak pernah mengaji di surau." (Gadis Pantai, hal. 263)

Kutipan tersebut menunjukkan bahwa Gadis Pantai berani menentang seorang Bendoro. Perlawanan tersebut sebenarnya tidak hanya didasari oleh naluri seorang ibu yang membela anaknya, tetapi juga karena proses mimikri yang telah dilalui oleh Gadis Pantai selama hidup di lingkungan keluarga bangsawan. Dia pun menjadi lebih berani dalam bertindak. Lingkungan tersebut telah memengaruhinya secara budaya untuk bagaimana bersikap dan menghadapi masalah.

\section{SIMPULAN}

Wacana poskolonial dalam novel Gadis Pantai karya Pramoedya Ananta Toer merupakan sebuah bentuk feodalisme yang terjadi dalam masyarakat setelah kemerdekaan. Kehidupan yang dilalui tokoh Gadis Pantai menggambarkan bagaimana dirinya harus melalui proses adaptasi di 


\section{DEIKSIS - JURNAL PENDIDIKAN BAHASA DAN SASTRA INDONESIA}

$\begin{array}{lrl}\text { lingkungan } & \text { keluarga } & \text { bangsawan dan } \\ \text { akhirnya melakukan } & \text { proses mimikr }\end{array}$ terhadap kehidupan bangsawan dan Bendoro. Gadis Pantai menjadi gambaran sebuah mimikri bahwa yang terjajah tidak selalu diam dan kuasa untuk melawan, yakni dilakukan dengan cara meniru bagaimana seorang Bendoro bertindak. Keberanian yang dilakukan oleh Gadis Pantai mengambarkan bahwa yang terjajah sebenarnya tidak menunjukkan ketergantungan pada Bendoro. Hal tersebut terbukti pada akhir cerita. Gadis Pantai bersedia meninggalkan lingkungan istana, tetapi dengan membawa anak yang baru dilahirkannya. Peminjaman elemen kebudayaan dan peniruan tersebut bisa jadi dilakukan secara alamiah melalui proses yang terjadi.

\section{E. DAFTAR PUSTAKA}

Arikunto, S. 2013. Prosedur Penelitian: Suatu Pende-katan Praktik. Jakarta: Rineka Cipta.

Barker, Chris. (2005). Cultural Studies: Theory and Practice. Australia: Sage Publication.

Banerjee, Suparno. (2014). "Melodrama, mimicry, and menace: Reinventing Hollywood in Indian science fiction films". South AsianPopular Culture, 2014. Vol. 12. No. 1. pp. 15-28.

Bhaba, Homi. K. (1994). The Local of Culture. London and New York: Routledge.

Brown, Alicia. (2016). "Mimicry and Acceptance". A Journal of Caribbean Culture. Pp 157-160.

Efendi, Agik Nur. (2016). "Membaca Resistensi Terhadap Kolonialisme Dalam Cerpen Samin Kembar Karya
Triyanto Triwikromo". Jurnal Pendidikan Bahasa dan Sastra. Vol. 16. No. 2 pp 225-234.

Faruk. (2001). Beyond Imagination, Sastra Mutakhir dan Ideologi. Yogyakarta: Gama Media.

Gandhi, Laela. 2001. Teori Poskolonial: Upaya meruntuhkan Hegemoni Barat. Yogyakarta: Qalam

Loomba, Ania. Colonialism/Postcolonialism. London: Routledge.

Miles, M. B. dan Huberman, A. M. 1992. Analisis Data Kualitatif: Buku Sumber Tentang Metode-metode Baru. Jakarta: UI-Press.

Ratna, N. K. 2004. Teori, Metode, dan Teknik Penelitian Sastra: Dari Strukturalisme hingga Postrukturalisme, Perspektif Wacana Naratif. Yogyakarta: Pustaka Pelaja.

Ratna, Nyoman Kutha. (2004). Teori, Metode, dan Teknik Penelitian Sastra. Yogyakarta: Pustaka Pelajar.

Watson, Jini Kim. (2014). "Imperial mimicry, modernisation theory and the contradictions of postcolonial South Korea". Postcolonial Studies. Vol. 10. No. 2. pp. 171-190. 